\title{
Free recall from unilingual and trilingual lists
}

\author{
P. D. MCCORMACK and JOSÉ A. NOVELL \\ Carleton University, Ottawa, Ontario K1S 5B6, Canada
}

\begin{abstract}
Three groups of 20 French-dominant female subjects were required to recall from 18 -word unilingual and trilingual lists, the languages being French, English, and Spanish. For items recalled from secondary memory, two of the three groups exhibited equivalent recall from the unilingual and trilingual lists, whereas the remaining group showed superior unilingual recall. For primary memory items, all three groups exhibited superior recall from unilingual lists. In trilingual-list recall, dominant-language items were superior in primary memory but inferior in secondary memory. These latter data were interpreted as being consistent with the notion that dominant-language items have priority in primary memory and that this produces output interference which is selective with respect to this class of items in secondary memory.
\end{abstract}

Free recall from a bilingual list appears to be equivalent to that from a unilingual list of the same length, in spite of the fact that the former setting imposes the additional demand on the subject of having to recall in the appropriate language (Kolers, 1965; Lambert, Ignatow, \& Krauthamer, 1968; Liepmann \& Saegert, 1974; Nott \& Lambert, 1968; Saegert, Obermeyer, \& Kazarian, 1973). The only exception to this finding has been reported by Tulving and Colotla (1970) where the best recall was from a unilingual list, the next best from a bilingual list, and the poorest recall was from a trilingual list. One of the purposes of the present study was to reinvestigate this phenomenon in the context of a unilingual-trilingual setting.

Another purpose of the investigation was to attempt to replicate, as well as to gain some additional understanding of, the observation that poorest recall from mixed-language lists is for dominant-language items (Nott \& Lambert, 1968; Tulving \& Colotla, 1970). Nott and Lambert (1968) defined dominance in terms of self-ratings of language skills, as well as by comparing reading times for passages in each of the subject's two languages. Tulving and Colotla (1970), on the other hand, based their definition on performance in unilingual settings. This latter criterion will be employed for the purposes of the present study, but it will be supplemented by additional criteria, all of which identify our subjects as being French dominant.

\section{METHOD}

The subjects were 60 female secondary-school students. French was their language of instruction, and it was also their principal means of communication at home. However, their

Support for this research was received under National Research Council of Canada Grant APA-78. The authors are indebted to Sister Paulette Navion. Directrice-Générale, Ecole Secondaire St. Joseph de Hull, for kindly providing access to subjects. Requests for reprints should be sent to $P$. D. McCormack, Department of Psychology, Carleton University, Ottawa, Ontario K1s 5 B6 Canada. milieu was such that they were exposed to the English language and would, from time to time, be required to use it. All 60 were enrolled in a Spanish-language course. They were randomly assigned to each of three groups. Group UT was required to recall from unilingual lists and then from trilingual lists. Group TU was given the trilingual lists first and the unilingual lists second. Group ALT received an alternating presentation of unilingual and trilingual lists.

The lists were developed from an original word pool of 673 high-frequency nouns taken from a frequency dictionary of Spanish words (Juillard \& Cheng-Rodriquez, 1964). These words, as well as their translations into the French and English languages, were presented to a group of 17 judges, all of whom were Spanish-language classmates of the experimental subjects. These judges were asked to read each of the 2,019 words and to eliminate any with which they were unfamiliar. Twenty additional judges, enrolled in a lower-level Spanish-language course, were asked to perform the same screening task. As a result, 120 Spanish, 81 English, and 7 French words were eliminated. These data provide additional evidence that the subjects were French dominant. Of the 88 words eliminated in the French and English languages, 27 had not already been discarded in Spanish. This left a pool of 526 Spanish words, as well as their translations into each of the other two languages, which was employed for the construction of the various lists.

All lists were 18 words in length. Each subject received 36 lists, 18 unilingual and 18 trilingual. Of the unilingual lists, six were in French, six in English, and six in Spanish. The 18 trilingual lists were designed such that all six orders of the three languages were employed. For each of these six orders, items from a given language were presented in blocks of either one, two, or three. The order in which the 18 lists was presented was randomly determined. For both unilingual and trilingual treatments, words were selected from the pool at random, with the constraint that a word, or either of its two translations in the case of trilingual lists, could not be repeated within any given list. The subjects were given a practice task $24 \mathrm{~h}$ in advance of the main session. All materials were taped for auditory presentation, and a single experimental session was employed for each of the three groups of subjects. The interword interval was $2 \mathrm{sec}$, and $2 \mathrm{~min}$ were given for written recall from each list. The interlist interval was $10 \mathrm{sec}$. The subjects were required to recall in the appropriate language in order to be credited with a correct response.

\section{RESULTS AND DISCUSSION}

Total recall from each of the three types of unilingual lists was examined with the purpose of checking, once more, that the subjects were indeed French dominant. 
Table 1

Mean Number of Words Recalled in English, French, and Spanish from Trilingual Lists for Primary and Secondary Memory

\begin{tabular}{lcccc}
\hline & \multicolumn{3}{c}{ Language } & \\
\cline { 2 - 4 } & French & English & Spanish & Total \\
\hline Primary Memory & 17.70 & 10.10 & 13.23 & 41.03 \\
Secondary Memory & 15.12 & 22.98 & 25.00 & 63.10 \\
Total & 32.82 & 33.08 & 38.23 & $104.13 / 324$ \\
\hline
\end{tabular}

The maximum number of words recallable for any given type of list was 108 , and the means were as follows: French $=39.57, \quad$ English $=36.44, \quad$ Spanish $=36.32$, $\mathrm{F}(2,144)=9.53, \mathrm{p}<.001$. The performance in these unilingual settings, therefore, supports the contention that the subjects' strongest language was French. Spanish, however, did not appear to be the weakest language, and this was possibly due to the fact that the experimenter was perceived in his role of Spanish teacher. There were also statistically reliable differences among the three groups of subjects, the mean number of words recalled being 38.18 for Group UT, 40.03 for Group TU, and 34.12 for Group ALT, F $(2,57)=9.42$, $\mathrm{p}<.001$. The poor performance of Group ALT might be attributed to the unblocked nature, at input, of their unilingual lists. This Group ALT effect was revealed in all subsequent analyses involving unilingual lists.

The next set of analyses compared unilingual and trilingual recall. The first of these examined secondary memory only, since this was where Tulving and Colotla (1970) observed superior recall from unilingual lists. The Tulving-Colotla procedure for defining secondary memory was employed. An item was assumed to be recalled from secondary memory if eight or more items intervened between its input and output. Items with lags of seven or fewer were considered as having been retrieved from primary memory. The mean number of items recalled from secondary memory was 63.45 for the unilingual lists and 63.03 for the trilingual lists, $F(1,57)<1.00$. These data are clearly consistent with the majority of studies, all of which have demonstrated no difference in recall between these two types of list. There was, however, an interaction in these data, $F(2,57)=4.54, \quad p<.025$, this being primarily attributable to the finding that Group TU exhibited the Tulving-Colotla phenomenon of superior recall from unilingual lists. The second analysis examined recall from both primary and secondary memory, a procedure which has been employed by the majority of investigators. The mean number of words recalled from unilingual lists was 112.33 , whereas that for trilingual lists was $104.13, \mathrm{~F}(1,57)=18.52, \mathrm{p}<.001$. This was the case for all three groups of subjects, since the $F$ for interaction was less than unity. Since there were no overall secondary-memory differences between the two types of lists, the superior performance on unilingual lists must be a primary memory phenomenon. Since this has now been revealed in both primary and secondary memory (Tulving \& Colotla, 1970), the statement that there are no differences in recall from unilingual and mixed-language lists must be seriously re-evaluated. Where no differences have been found, the effect might have existed in either primary or secondary memory, but not both, but because of a lack of statistical power, the null hypothesis was retained. It is also of interest to note that, whereas recall is sometimes superior in the unilingual setting, recognition is best in a bilingual context (McCormack \& Colletta, in press).

The next set of analyses was concerned with the observation that items from the dominant language show poorest recall from mixed-language lists (Nott \& Lambert, 1968; Tulving \& Colotla, 1970). The first analysis examined recall from the secondary-memory component of bilingual lists for each language separately. The only statistically significant effect was that for language, $F(2,114)=45.62, p<.001$. The means for each of these three treatments are shown in the second row of Table 1. It is clear, from an examination of the table, that the phenomenon is replicable, poorest recall being for items from the subject's strongest language. A similar analysis of recall from primary memory, on the other hand, revealed superior recall of items from the dominant language. Again, the only statistically reliable effect was that for language, $F(2,114)=33.00, p<.001$. The three means are shown in the first row of Table 1. These data, in conjunction with those involving recall from secondary memory, are consistent with the notion that a subject "dumps" items from primary memory and then searches secondary memory in an attempt to optimize recall. This type of information processing is characterized by the fact that items from the dominant language receive priority in primary memory, and somehow this produces output interference which is selective with respect to items from the dominant language in secondary memory.

\section{REFERENCES}

Juillard, A., \& Cheng-Rodriguez, E. (Eds.), Frequency dictionary of Spanish words. London: Mouton, 1964.

Kolers, P. A. Bilingualism and bicodalism. Language and Speech, $1965,8,122-126$.

Lambert, W. E., Ignatow, M., \& Krauthamer, M. Bilingual organization in free recall. Journal of Verbal Learning and Verbal Behavior, 1968, 7, 207-214.

Liepmann, D., \& Saegert, J. Language tagging in bilingual free recall. Journal of Experimental Psychology, 1974, 103, 1137-1141.

McCormack, P. D., \& Colletta, S. P. Recognition memory for items from unilingual and bilingual lists. Bulletin of the Psychonomic Society, in press.

Nott, C. R., \& Lambert, W. E. Free recall of bilinguals. Journal of Verbal Learning and Verbal Behavior, 1968, 7, 1065-1071.

Saegert, J., Obermeyer, J., \& Kazarin, S. Organizational factors in free recall of bilingually mixed lists. Journal of Experimental Psychology, 1973, 97, 397-399.

Tulving, E., \& Colotla, V. A. Free recall of bilingual lists. Cognitive Psy chology, 1970, 1, 86-98.

(Received for publication May 8, 1975.) 